\title{
A contribuição da hermenêutica crítica de Jürgen Habermas para a Terapia Ocupacional Social
}

\author{
Regina Célia Fiorati \\ Curso de Terapia Ocupacional, Faculdade de Medicina de Ribeirão Preto - FMRP, Universidade de São \\ Paulo - USP, Ribeirão Preto, SP, Brasil
}

\begin{abstract}
Resumo: Introdução: Trata-se de uma reflexão crítica sobre a contribuição do referencial filosófico de Jürgen Habermas para a prática social em Terapia Ocupacional. A Terapia Ocupacional em Contextos Sociais tem se consolidado promovendo atenção a pessoas, grupos e população em vulnerabilidade social que, a partir de uma dada orientação político-econômica, integra uma zona de pobreza, desemprego e ruptura com as redes de suporte social. Objetivo: Discutir sobre as contribuições da Teoria da Ação Comunicativa de Habermas para a Terapia Ocupacional em Contextos Sociais, através da noção de consensos fundados como instâncias de entendimento mútuo entre homens e mulheres sobre algo no mundo da vida. Metodologia e discussão: Busca-se apresentar a reflexão proposta mostrando-se como a filosofia habermasiana revela-se útil na construção de estratégias de enfrentamento das problemáticas sociais através da formação de consensos democráticos para a produção de projetos de ação, com base na proposta de formação intersetorial entre âmbitos da administração pública e da sociedade civil. Ainda, enfoca-se a experiência da Terapia Ocupacional no Campo Social que o Curso de Terapia Ocupacional da USP de Ribeirão Preto vem realizando junto a pessoas em situação de rua e que vem propondo a estratégia da intersetorialidade para a elaboração de políticas publicas e estratégias de ação no combate à pobreza e vulnerabilidade social.
\end{abstract}

Palavras-chave: Vulnerabilidade Social, Terapia Ocupacional, Assistência Social, Políticas Públicas, Democracia.

\section{The contribution of the critical hermeneutic of Jürgen Habermas to social occupational therapy}

\begin{abstract}
Introduction: This critical reflection addresses the contribution of the philosophical framework of Jürgen Habermas to the social practice of occupational therapy. Occupational therapy has been consolidated in social contexts providing care to people, groups and populations in situations of social vulnerability, which according to a political-economic orientation, includes poverty, unemployment, and ruptured social support networks. Objective: To discuss the contributions of Habermas's Theory of Communicative Action to occupational therapy in social contexts through the notion of consensus, founded as a forum of mutual understanding between males and females about something in the world of life. Method and discussion: We also seek to propose a reflection showing how Habermas's theory is useful in the construction of coping strategies to deal with social issues, through democratic consensus toward the production of action projects based on inter-sector cooperation between public administration and civil society. We also focus on the experience of occupational therapy in the social field that the Occupational Therapy program administered by the University of Sao Paulo - USP at Ribeirao Preto has carried out with homeless individuals and proposed a strategy of inter-sector cooperation to develop public policies and action strategies to fight poverty and social vulnerability.
\end{abstract}

Keywords: Social Vulnerability, Occupational Therapy, Social Assistance, Public Policies, Democracy.

Autor para correspondência: Regina Célia Fiorati, Curso de Terapia Ocupacional, Faculdade de Medicina de Ribeirão Preto, Universidade de São Paulo, Av. Bandeirantes,3900, CEP 14049-900, Ribeirão Preto, SP, Brasil, e-mail: reginacf@fmrp.usp.br

Recebido em 25/1/13; $1^{\text {a }}$ Revisão em 14/5/2013; $2^{\text {a }}$ Revisão em 4/7/2013; Aceito em 15/7/2013. 


\section{Introdução}

A Terapia Ocupacional em Contextos Sociais é um campo de conhecimento e prática da Terapia Ocupacional consolidado e reconhecido recentemente (década de 1990), mas que se encontra ainda em processo de construçáo no que diz respeito ao escopo teórico-metodológico, na perspectiva de formar ou constituir um campo epistemológico terapêutico ocupacional para subsidiar a produçáo de conhecimento para a prática social.

Para evitarmos repetições desnecessárias e para adentrarmos a história, concepçôes e metodologias da Terapia Ocupacional Social, estaremos nos reportando ao capítulo Terapia Ocupacional na Prática Social, escrito por Denise Dias Barros, Roseli Esquerdo Lopes e Sandra Galheigo no livro Terapia Ocupacional: Fundamentação e prática (2007), no qual as autoras descrevem o percurso histórico de uma prática social na Terapia Ocupacional, desde o início de seu desenvolvimento até o momento atual, a partir do qual uma nova Terapia Ocupacional em Contextos Sociais consolida-se e passa a ser reconhecida enquanto campo específico de conhecimento e atuação. E salientam que na atualidade a Terapia Ocupacional Social também inaugura referenciais teóricos específicos, bem como um corpo metodológico próprio para prática profissional específica no campo social.

De acordo com as tendências contemporâneas, pode-se observar que a corrente da Terapia Ocupacional Social que prevalece é aquela que atua junto a populações e segmentos sociais em situação de vulnerabilidade social, a partir das rupturas que tais segmentos vão sofrendo na estrutura de sua rede de suporte social, bem como a partir da reproduçáo de relaçóes precarizadas de trabalho e de vida. Tais condiçôes de vida, em que se encontram parcelas crescentes da populaçáo mundial e brasileira, são decorrentes de uma orientação econômico-política globalizada na qual há uma imposição da economia e da racionalidade do capital sobre a dimensão social e humana, produzindo imensas desigualdades sociais. Da mesma forma, a tessitura social é entendida como uma rede formada por interesses e poderes em constante conflito, os quais fundamentam a dinâmica das transformaçôes sociais (BARROS; LOPES; GALHEIGO, 2007).

Nessa perspectiva, propóem-se a concepção do campo social como área interdisciplinar e intersetorial à qual a integração do terapeuta ocupacional ocorreria com base em uma metodologia própria, voltada para a criaçáo e fortalecimento de redes sociais de suporte de pessoas, grupos e comunidades, construção de projetos sociais que visem à emancipação e à consolidação da cidadania de grupos, pessoas e projetos de vida que possibilitem a criação de autonomia e autodeterminação. Assim como as atividades, recursos tradicionais terapêuticoocupacionais, que são eminentemente entendidas como meio de vinculação, intermediação entre o micro e o macrossocial, para a açáo voltada para o coletivo e para a cultura (MALFITANO, 2005).

Para tanto, dentre vários referenciais teóricos, destaca-se o referencial teórico-filosófico que vem sustentando a construção teórico-metodológica e prática desse campo da Terapia Ocupacional como aquele constituído pelas análises de Robert Castel $(1997,2001)$, o qual propicia marcos para avaliação da etapa de vulnerabilidade em que se encontram determinados sujeitos ou grupos, a partir dos conceitos de vulnerabilidade e desfiliação, utilizados como critérios de identificação de inclusão/ exclusão das esferas do trabalho e redes sociais de suporte. Além desse, outros referenciais somaram-se para constituir o escopo teórico que ampara toda a crítica social e política subjacente à prática no campo social: Karl Marx, Gramsci, Franco Baságlia, Michel Foucault, Erving Goffman, Paulo Freire, entre outros. De maneira geral, tais referenciais propiciaram a crítica macrossocial aos processos de institucionalizaçáo das práticas sociais e das formas de atençáo a determinados segmentos sociais, bem como as práticas assistenciais alienadas histórica e politicamente e centradas nos aspectos funcionais individuais (BARROS; LOPES; GALHEIGO, 2007).

Sem abandonar tais referências e enfatizando sua importância para a Terapia Ocupacional Social, percebe-se que outro referencial filosófico vem contribuir para a construção metodológica da Terapia Ocupacional Social, bem como na criação de tecnologias de atuação no campo social, sendo esse referencial representado pela hermenêutica crítica de Jürgen Habermas. A contribuição desse referencial será analisada, neste trabalho, pontualmente, no que diz respeito à ação política da Terapia Ocupacional em sua inserção em órgãos formuladores e gestores das políticas públicas, a qual ocorre complementarmente à atençáo territorial e comunitária aos grupos e populaçóes.

Partindo-se de uma experiência prática que vem sendo desenvolvida no campo social pelo Curso de Terapia Ocupacional da Faculdade de Medicina de Ribeirão Preto da Universidade de São Paulo (TO-FMRPUSP) junto a pessoas em situação de rua do mesmo município, percebe-se a importância desse referencial filosófico como subsídio teórico para a construção de açôes intersetoriais propostas como 
estratégia de intervenção a setores da administração pública e da sociedade civil do município, no sentido da criação de políticas públicas voltadas para o enfrentamento da vulnerabilidade social, erradicação da pobreza e democratizaçáo da sociedade.

A experiência do curso de TO-FMRPUSP no campo social, referida acima, desenvolve-se através de três iniciativas: estágio profissionalizante com pessoas em situação de rua no Centro de Referência e Assistência Social Especializado em Pessoas em Situação de Rua (CREAS-POP) de Ribeirão Preto; evento científico realizado com a participação de diversos setores da administraçáo pública e sociedade civil do município e CREAS-POP; e pesquisa científica com pessoas em situação de rua, que se encontra em desenvolvimento e tem como objetivos estudar as situaçóes e momentos nos quais ocorreram as rupturas com os sistemas de redes de suporte social e com o trabalho formal e realizar um vídeo documentário que servirá como dispositivo de discussão na sociedade.

A partir do evento citado, elaborou-se documento com propostas de políticas públicas, assistenciais e de estratégias de intervenção, bem como da constituição de redes de atenção e açóes intersetoriais junto a pessoas em vulnerabilidade social. Tal documento foi entregue às secretarias municipais de Saúde, Assistência Social, Cultura e Educação, à Câmara de Vereadores, à Prefeitura e aos candidatos a cargo de prefeito que, na época (agosto de 2012), se encontravam em campanha eleitoral. A ênfase do documento e das discussóes que ocorreram no evento deu-se na constituição de ações intersetoriais e formação de redes de atenção, por isso nossa discussão se apoiará no foco da intersetorialidade.

A teoria crítica de Habermas, mais especificamente a Teoria da Ação Comunicativa, mostra-se útil, principalmente no que diz respeito à noção apresentada por Habermas (1988) sobre os "consensos fundados" como instâncias de construçôes dialógicas entre dois ou mais sujeitos que, na perspectiva de um entendimento mutuo a respeito de algo no mundo da vida e por meio de debate radical, entrariam em acordo sobre temas e açôes para a construção de projetos de ação social democraticamente orientados.

A intersetorialidade, entendida como processos organizados e coletivos de açóes deliberadas que pressupóem a interação entre diferentes segmentos e setores administrativos e da sociedade civil com vistas a criar estratégias consensuais de ação social, interfere na produção social e subjetiva ao produzir efeitos sobre os modos de ser e de atuar dos atores sociais, usuários e gestores de serviços e organizaçóes (NAVARRO, 2011). Constitui, portanto, instâncias de interação e discussão entre pessoas para tomada de decisóes sobre algum projeto de ação social, ou seja, constitui um processo comunicativo que pretende um consenso sobre algo no mundo social dos sujeitos imbricados no processo.

Portanto a necessidade de formação de consensos orientadores da ação social já aparece explicita nessa primeira definição de no que consiste uma constituição intersetorial.

Nesse sentido, este trabalho propóe uma reflexão crítica sobre a importância da Teoria do Agir Comunicativo de Jürgen Habermas na fundamentação teórico-metodológica para a prática social em Terapia Ocupacional com base nas propostas de formaçóes intersetoriais para elaboração de políticas públicas sociais norteadoras de estratégias de intervenção junto à população em vulnerabilidade, a partir da relevante concepção introduzida por Habermas de "consensos fundados", expressão da condição antropológica da competência comunicativa dos homens e mulheres em interaçáo, na busca de exercícios de plena democracia.

Para isso, inicialmente, discorre-se sobre algumas formulaçôes teóricas desse filósofo, a fim de melhor compreender seu pensamento.

Em seguida, em um segundo subitem, passa-se à reflexão de como as formulaçóes da teoria habermasiana podem contribuir para a Terapia Ocupacional Social, através da discussão sobre a importância da intersetorialidade para a construção de projetos sociais e políticas públicas de enfrentamento das problemáticas sociais emergentes.

Por último apresenta-se um relato sumário de algumas açóes desenvolvidas pelo Curso de Terapia Ocupacional FMRPUSP em contextos sociais, as quais vêm dando ênfase à criação de redes intersetoriais para a elaboração de políticas, propostas e estratégias de enfrentamento da vulnerabilidade social.

\section{Habermas, dialogicidade e intersubjetividade: Bases de uma teoria da comunicação voltada para a emancipação}

Habermas é um dos filósofos contemporâneos que iniciou sua produçáo intelectual ligado aos autores da Escola de Frankfurt e, a partir da década de 70 do século XX, passou a criticar o conceito de razão decorrente do paradigma da consciência para orientar-se segundo proposiçóes da guinada linguística da filosofia, a qual retira a 
autoconsciência do sujeito do seu lugar de condição da racionalidade para delegar à linguagem o instrumento de racionalidade, pelo qual se pode ter acesso aos conteúdos do pensamento e à dimensão intersubjetiva da produção dos conhecimentos e das açôes humanas (ARAGẪO, 2002).

Como herança da Escola de Frankfurt e da teoria crítica, Habermas elaborou a crítica da ideologia e da cultura com base em sua crítica da sociedade tecnocrática. A teoria crítica, visão teórico-filosófica proposta por Theodor Adorno e Max Horkheimer, principais representantes da Escola de Frankfurt, defende que, sob o signo de uma racionalidade instrumental autonomizada, a racionalidade $\mathrm{da}$ dominaçáo da natureza se liga à irracionalidade da dominaçáo de uma classe de homens sobre outras e que as forças produtivas imobilizadas operam a estabilização de relações de produção alienadas. Essa concepção inverte as esperanças de Marx, que pensava que a ciência e a técnica representariam um potencial emancipatório, mas que se transformam, na teoria crítica, em forças de repressão social e total alienação, de tal forma que a própria razão, confundindo-se com a racionalidade instrumental, passa a ser entendida como instrumento de exploraçáo do homem, opressão e violência (FIORATI, 2010, 2012).

Habermas distancia-se dos preceitos da teoria crítica, por considerar que ela se atrela ainda ao paradigma da consciência, e refere outro paradigma da razão, o qual substitui a consciência pela linguagem como critério de racionalidade. Dessa forma, para Habermas (1987), ao analisar-se a comunicação cotidiana, infere-se uma competência universal a todo falante e agente adulto, ou seja, a capacidade comunicativa de dizer algo que se espera que o outro compreenda e sobre o que se busca concordância, mesmo que se parta de um processo de conflito, discordância e discussão. Essa capacidade, por sua natureza essencialmente dialógica e intersubjetiva, por sua vez permitiria supor uma predisposição para o entendimento mútuo entre os homens, que se contraporia ao desejo de domínio da razáo instrumental.

Nesse sentido, para este trabalho há três enfoques do pensamento habermasiano que nos interessam. $\mathrm{O}$ primeiro diz respeito à relação entre a dialética do trabalho e a da interaçáo, o segundo baseia-se nas reflexões sobre as funçóes que assumem a técnica e a ciência enquanto forças de coesão ideológica na sociedade contemporânea e que, ao tecnificarem todas as dimensôes da vida social e política, passam a colonizar a esfera da interação humana. O terceiro enfoque relaciona-se à possibilidade apresentada por Habermas (1989) da constituição de consensos normativos dialogicamente construídos e fundados sobre bases democráticas, na condição da isenção de coerções e violências no encontro interdiscursivo intersubjetivamente mediado pela linguagem. Esse último aborda a Teoria da Ação Comunicativa, a partir da qual o autor propóe uma racionalidade fundada na intersubjetividade e na interaçáo humana impondo-se à racionalidade instrumental na condução de projetos de ação social (HABERMAS, 1988).

Habermas (1987) distingue entre duas esferas da condição humana que embora na prática permaneçam interdependentes analiticamente tornam-se irredutíveis uma à outra: o trabalho como ação teleológica abarcando racionalidade instrumental orientada pelo princípio técnico e a interação socialhumana fundada na ação comunicativa. Segundo o autor, há uma relação recíproca entre trabalho e interação, sendo que não há uma relação de derivaçáo automática uma da outra, mas uma relação dialética. $\mathrm{O}$ trabalho como ação dirigida a fins determinados é constituído por duas dimensóes: a ação racional apoiada sobre regras técnicas e saber determinado e a ação estratégica, que visa um sucesso efetivo segundo critérios de utilidade com relação às finalidades propostas. Em outra perspectiva, a interação refere-se à ação comunicativa fundada por normas consensuais, apoiada na intersubjetividade que visa ao entendimento mútuo, a partir do qual as pessoas se colocam de acordo em relaçáo a projetos e planos de ação.

$\mathrm{Na}$ sociedade contemporânea há um processo denominado por Habermas (1987) colonização do mundo da vida pela técnica e pela ciência. Tal processo seria causado pela fusáo da técnica e da ciência com os sistemas de dominaçáo, remetendo à teoria sobre a ideologia tecnocrática como organização social-ideológica decorrente de um estágio de açốes intervencionistas do Estado como resposta a reivindicaçóes de movimentos sociais e para manutenção dos modos de produção capitalista, processo que sugere uma melhoria das condiçóes de vida das massas com base no desenvolvimento técnico-científico e na substituição da discussão política pelas orientaçóes técnicas. Ciência e tecnologia passam a funcionar como as principais forças produtivas e de coesão ideológica, como a forma privilegiada de legitimação da dominação, manutenção de um processo de despolitização das massas e de ocultação da violência social subjacente às relaçóes de produção e ao modo de existência imposto.

Assim, a sociedade se unidimensionaliza e passa a ser a esfera da administração total. Da mesma 
forma, os aparelhos de poder instrumentalizam-se como órgãos executivos da razão científica e técnica. Portanto, a dominação, segundo essa perspectiva, se exerce enquanto ciência e tecnologia. O progresso autônomo da ciência e da técnica vai determinar o desenvolvimento da vida social. O Estado absorve a lógica específica da razáo técnica e científica e passa a orientar suas decisóes não pela prática, mas sim tecnicamente. Essa ideologia propóe uma perspectiva segundo a qual o desenvolvimento do sistema social é determinado pela lógica do progresso técnico-científico e o efeito imediato é a despolitização das massas, a ocultação dos verdadeiros interesses que subjazem a esse funcionamento social e geram o impedimento de a opinião pública manifestar-se em questionamentos críticos, pois na medida em que os fundamentos do funcionamento tecnocrata respondem somente a imperativos de uma racionalidade técnica, tornam-se imunes a qualquer contestação (HABERMAS, 1987).

Além disso, como a ideologia tecnocrática vai apresentar questóes práticas sob a forma de questôes técnicas, exclui do debate público os temas significativos para a práxis e produz um resultado ainda mais grave: a invalidação na consciência dos homens da distinção entre ação instrumental e ação comunicativa. O Homem passa a autoobjetivar-se exclusivamente na perspectiva da ação instrumental e do comportamento adaptativo e a ação comunicativa é, entâo, absorvida pela ação instrumental (WIGGERSHAUS, 2006).

Habermas (1988), contudo, traz a proposição de racionalidade apoiada em ação comunicativa que se contrapóe à racionalidade instrumental. A racionalidade comunicativa, portanto, permeia a dimensão na qual ocorrem os processos da interação humana realizados pela intercomunicabilidade apoiada nas trocas intersubjetivas e simbolicamente mediada pela linguagem. De acordo com o autor, é essa racionalidade que possibilita a construçáo de projetos sociais dialogicamente instaurados, isto é, a construção coletiva apoiada no diálogo, a partir do qual os discursos tenham o mesmo estatuto de validação. Dessa forma, o filósofo propóe uma ação comunicativa livre e isenta de coaçóes, que se colocaria na base da formação de consensos normativos para viabilização de projetos sociais multiculturais e processo civilizatório apoiado em valores de solidariedade social.

Para que o enfoque teórico que trabalha as açóes comunicativas sob determinadas condições de validação possa tornar-se útil, não basta que os homens se comuniquem entre si, eles precisam fazê-lo sob determinadas condiçôes. Como ressalta
Aragão (2002), Habermas propóe uma "situação ideal de fala" na qual há uma exigência de simetria de posiçóes e discursos, uma igualdade de chances entre todos os sujeitos que necessitam estar imbricados na circunstância dialógica, ou seja, a ação comunicativa constituída tem de se dar livre de coaçôes e restriçôes aos interesses de qualquer participante. Para isso, o filósofo propóe uma teoria do agir comunicativo, a qual se daria sob determinadas condiçóes de validade. Assim como propóe que, integrando o processo argumentativo de discussáo que envolve toda interação comunicativa, há uma força que faz com que prevaleça o melhor argumento, apoiado pelo critério de uma racionalidade que sustentaria as decisóes para um bem comum e, portanto, que diferenciaria, assim, os consensos fundados verdadeiros dos falsos.

Essa proposição habermasiana gerou imensa polêmica no mundo da filosofia, principalmente a promovida pelo neopragmatismo, representado por Richard Rorty, o qual questionou a pretensão de uma universalidade e de verdade absoluta embutida na proposta do "melhor argumento" presente nas proposiçóes de Habermas, levando-o, irremediavelmente, a um "universalismo kantiano", contra as orientaçóes pragmáticas voltadas para o contextualismo (SOUZA, 2005).

A essa crítica ressaltamos outra importante, que cerca a questão do conflito. Para alguns críticos, Habermas oculta a questão do conflito presente nas relaçóes sociais humanas sob o manto da busca de entendimento mútuo como uma condição antropológica do ser humano, presente e atualizado pela capacidade de comunicabilidade linguística da espécie.

Segundo Aragão (2002), Habermas, no que diz respeito à primeira crítica sobre a contraposição de universalidade e contextualismo, não propóe que os consensos fundados tenham uma força de verdade universal, mas que são contextuais na medida em que eles se transformam e mudam o objeto que fundam os acordos promovidos historicamente, porque os próprios "melhores argumentos" que fundam os consensos, mudam histórica e culturalmente.

Em relação à segunda crítica, Aragão (2002) argumenta que para Habermas não há supressão do conflito, mas que ele está implícito em sua teoria do discurso, momento ou situaçáo de fala ou de interação comunicativa, no qual ela é interrompida por um questionamento. A partir daí ocorre um processo de discussáo, de debate radical, contudo, ainda que haja proposiçôes contrapostas, o debate está voltado, em toda interação social, para a busca de um entendimento dos participantes sobre algo 
no mundo objetivo, social e subjetivo, ou mais exatamente, àquilo que o filósofo denomina de mundo da vida.

Entretanto, há, ainda, outra dificuldade: a prática comunicativa cotidiana é muito distorcida e está submetida exatamente às mesmas coercitividades, as quais Habermas salienta não poderem ocorrer em uma situação ideal de fala. Ou seja, a prática comunicativa dos homens é repleta de preconceitos e atravessamentos de poderes e interesses particulares que são impostos aos públicos de forma contínua. Nessa dificuldade, Habermas (2007) responde que os processos comunicativos humanos que fundam os consensos éticos para a ação social são movidos por interesses que também guiam as açóes de produçáo de conhecimento, a saber: pela atitude de resolver problemas diante dos riscos impostos por um ambiente complexo; a justificação das alegaçôes de validade diante de argumentos opostos orientados por interesses opostos e que estão na raiz dos jogos de poder; e um aprendizado histórico cumulativo que depende, permanentemente, de reexames críticos dos próprios erros. Por isso, a saída habermasiana para esse problema é a proposição de um criticismo permanente e a denúncia crítica das interações comunicativas contaminadas por poderes particulares, os chamados, pelo filósofo, de falsos consensos.

Dessa maneira, Aragão (2002) conclui que em Habermas o conceito de racionalidade é indissociável da prática social fundada na intersubjetividade do entendimento, contudo o filósofo busca, igualmente, superar o conceito de racionalidade instrumental, ampliando a noção de razáo para o de uma razão que contém em si as possibilidades de reconciliação consigo mesma, segundo uma razão comunicativa. Portanto, Habermas não se posiciona contra a racionalidade instrumental, da ciência e da técnica, na medida em que essas são indissociáveis do processo de autoconservaçáo do homem. Para ele, a ciência e a técnica ampliam as possibilidades humanas, libertando o homem do jugo das necessidades materiais; o desenvolvimento da espécie humana, resultado do processo histórico do desenvolvimento tecnológico, institucional e cultural, é, portanto, processo interdependente.

Entretanto, a razão deve submeter a racionalidade instrumental à comunicativa, para que, na prática social, prevaleça a ação comunicativa. Em certo sentido, Aragão (2002) enfatiza que, assim caracterizada, a ação comunicativa é uma ação social que busca a intersubjetividade do entendimento tanto no plano do conhecimento, quanto no da ação. Assim, assume função dupla: tanto social quanto epistemológica, fundamentais para a coesão social e para a construção de uma crítica, buscando a emancipação humana e social.

Contemporaneamente, Habermas (2012), ao manifestar preocupação com a incapacidade de a política controlar a economia, a perda de sentido e de legitimaçáo da própria política diante dos cidadãos e com a necessidade de resgatar a dimensão da participaçáo democrática das pessoas, quer nos processos decisórios supranacionais, quer na gestão das políticas econômicas e financeiras, propôe uma reconfiguração da relação entre Estado e sociedade a partir da qual os processos decisórios gerais, tanto no que diz respeito à economia e finanças quanto à esfera política, devem, necessariamente, transcender os espaços tradicionais dos poderes públicos, dos parlamentos e das esferas administrativas de governo para incluir a sociedade civil. Embora nessa obra ele não tenha citado sua Teoria da Ação Comunicativa, os princípios básicos dessa teoria estão presentes quando deixa explícitas as intençóes mediante a crítica de que não pode haver uma real solidificação democrática sem a inclusão dos representantes civis da sociedade e dos movimentos sociais organizados nas esferas decisórias centrais do Estado e da sociedade. Isso pressupõe uma reorganização das instâncias de exercício do poder que poderia se concretizar a partir de formaçôes interdisciplinares e intersetoriais responsáveis pela formulação, implantação e gestão de políticas públicas.

\section{Intersetorialidade, Terapia Ocupacional Social e consensos fundados}

A intersetorialidade entendida como uma forma de gestão das políticas públicas encontra-se em construção enquanto conceito por ter-se apresentado na contemporaneidade como uma necessidade histórica frente às questóes socioculturais de grande complexidade, polissêmicas e multifacetadas que surgem nessa etapa histórica humana (CASTELLS, 2011).

A lógica de uma interação de mútuo entendimento intersetorial a respeito de um ou mais projetos ou questóes sociais apresenta-se como alternativa a uma anacrônica lógica setorial, fragmentada, vertical e autônoma em relaçáo a outros setores, que vão reproduzindo, cada setor em sua esfera de atuação, suas açôes mais ou menos independentes umas das outras (NASCIMENTO, 2010).

A intersetorialidade vem sendo entendida como uma dinâmica importante na construção 
de mecanismos de coesão social numa sociedade globalizada, diante de um capitalismo transnacional, a partir do qual as transformaçóes das relaçóes internacionais levam a uma constelaçáo pós-nacional em que as dimensôes econômicas se impóem às necessidades sociais e os Estados-nação não conseguem manter suas políticas sociais de bem-estar e nem intervir mais como uma instância reitora entre os interesses do capital e as sociais (SORJ; MARTUCCELLI, 2008).

Embora exista um debate sobre a importância das políticas setoriais na garantia do repasse dos devidos recursos para sua implementação e na descentralização por setores, a defesa da intersetorialidade apoia-se na relevância de ser considerada categoria chave na compreensão dos rumos, do alcance e da potencialização das intervenções, mostrando-se como um mecanismo de inovação e fortalecimento da gestão pública em face de problemáticas complexas como: combate à pobreza, reduçấo das desigualdades sociais e programas de transferência condicionada de renda nos estados e municípios, exigindo a articulação de várias áreas da política social como educação, assistência social, trabalho etc. (MINAYO-GOMES, 2011; MAGALHÁES et al., 2011).

Segundo Azevedo, Pelicioni e Westphal (2012), a intersetorialidade tem o potencial de revitalizar as políticas, entretanto evidenciam-se alguns problemas quanto à sua implementação, relacionados ao despreparo político e técnico dos gestores e dos profissionais para assumirem a perspectiva intersetorial, ao não conseguirem se desvencilhar de questôes administrativas que se impóem como entraves à articulaçáo das açóes. Entretanto, a partir da superação desses problemas, a intersetorialidade mostra-se dispositivo potente para se trabalhar, governar e construir políticas públicas em uma perspectiva de superação das fragmentaçóes de conhecimento e estruturas sociais e que produz efeitos significativos na integração de açôes para responder a determinadas problemáticas.

Nesse sentido, Mendes (2011) destaca o valor da dialogicidade na intersetorialidade. Ou seja, náo basta uma superposição de olhares interdisciplinares, mas o diálogo resultante de uma interface recíproca permanente. Nesse aspecto, a proposição de consensos fundados de Habermas é coincidente, já que para haver uma verdadeira construção coletiva e coordenada para uma ação social é necessária uma autêntica simetria dialógica e intersubjetiva. Daí a necessidade da inclusão da sociedade civil, além dos órgãos públicos ou privados, na intersetorialidade.

A Terapia Ocupacional em Contextos Sociais tem sido construída e aponta-se como metodologia principal, aquela que responda às necessidades impostas por grupos, pessoas e comunidades em vulnerabilidade social, marcados pela condiçáo de exclusão dos espaços e serviços disponibilizados à sociedade em geral, das condiçóes de reprodução material e simbólica da vida e com rupturas em suas redes de suporte social. Assim preconiza-se uma metodologia que leve à construção de instrumentos que possam interpretar a realidade em suas interfaces sociais, culturais, históricas, políticas e econômicas. Da mesma forma, as ações práticas inserem-se em campo interdisciplinar e intersetorial (BARROS; LOPES; GALHEIGO, 2007).

Nessa perspectiva, a Terapia Ocupacional insere-se na esfera política do campo social em um contexto em que a assistência social adquire a condição de política pública, a partir da formulação e implantação das diretrizes organizativas e operacionais da Política Nacional de Assistência Social e do Sistema Único de Assistência Social (SUAS): em junho de 2011, através da resolução n. 17 do Conselho Nacional de Assistência Social (CNAS), a Terapia Ocupacional é reconhecida enquanto uma das categorias profissionais de nível superior que atendem as especificidades da atenção socioassistencial e passa a integrar o rol das funçôes essenciais do SUAS (ALMEIDA et al., 2012).

Dessa forma, para contemplar a articulação entre o micro e o macrossocial através de açóes que busquem a compreensão e a transformação da realidade partindo das vivências subjetivas das pessoas atendidas, para contextualizá-las em vivências coletivas e grupais, assim como a compreensão das condiçóes historicamente produzidas pela tradicional formação cultural exclusora brasileira e pelas desigualdades sociais, e para a busca de enfrentamento dessa realidade e o resgate de cidadania plena, coloca-se para a Terapia Ocupacional o desafio de construir tecnologias de intervenção dentro do contexto da assistência social. Considerando-se que essas questóes sociais remetem a complexidade e multidimensionalidade, aponta-se a necessidade de que as estratégias devem passar pela ação intersetorial, e, para tanto, é necessária a criação de fóruns intersetoriais que possam discutir, elaborar e implementar políticas públicas, através do que vimos chamando, baseados no referencial teórico em questão, de consensos fundados.

Não se trata de contextualizar os consensos fundados como referencial metodológico para as açóes intersetoriais de um ponto de vista administrativo e técnico, apenas como sobreposiçấo de setores e pequenos poderes interessados, mas como uma prática emancipadora a partir de pequenas iniciativas locais de interação humana, para entendimento 
mútuo a respeito de questôes e problemas sociais que merecem estudos e propostas de intervenção complexa, decorrentes de consensos eticamente fundados com base na açáo de coletivos humanos de trabalho social. Trata-se, portanto, de focalizar a atenção na importância da contribuição da produção de consensos locais, provisórios, atuais e que, ao mesmo tempo, apontem na direção de permitir o esboço de uma forma de vida societária democrática, pluralista e igualitária.

Na história brasileira de redemocratização social e política da sociedade, a partir dos anos 1980, há muitos exemplos desses coletivos formadores de consensos para a ação social, nem sempre harmoniosos e quase sempre com muitos conflitos internos mas que, mesmo assim, e talvez por isso mesmo, apontaram e ainda apontam, mesmo com algumas deficiências, para uma prática democrática voltada para a resolução de problemas, elaboraçáo e implementação de políticas públicas e até de governabilidade social, entre outras coisas. O exemplo maior desses coletivos são os chamados Conselhos. A Reforma Sanitária Brasileira apostou muito, em sua implementação e na implantação do SUS, na constituição dos Conselhos de Saúde, como materialização de um de seus princípios básicos, representado pela necessária participação e controle da sociedade sobre o SUS e sobre as políticas de saúde.

Pode ser que a força da proposta dos consensos fundados como orientadores para a ação social esteja na crença de Habermas de que a linguagem, como instrumento básico da capacidade comunicativa humana, esteja orientada para o entendimento mútuo (e implicitamente para o exercício da democracia radical) e não para a dominação, como uma racionalidade comunicativa imperando sobre toda dimensão da instrumentalidade humana, contendo, por si só, uma promessa de emancipação social da espécie humana. Para Habermas (1989), a simples denúncia de uma prática comunicativa marcada por coerçóes e violências já é promissora de uma dimensão e possibilidade emancipadora.

Certamente, para a açáo emancipadora da humanidade não bastarão consensos fundados, tampouco somente ações de enfrentamento revolucionário. Provavelmente serão necessárias essas duas dimensôes de ação e muitas outras açóes ainda impensadas. Para nosso intuito, neste trabalho, basta a utilidade, com base em uma dimensão pragmática, que a teoria da Ação Comunicativa de Habermas e dos consensos fundados apresenta para a prática social em Terapia Ocupacional. E, nesse sentido, tal referencial vem se mostrando útil para a prática terapêutica ocupacional que, no campo da assistência social, pode propor, com base na constituição de fóruns intersetoriais, o estabelecimento de consensos éticos e fundados como orientadores para a ação social no enfrentamento da vulnerabilidade social, da pobreza e das desigualdades sociais.

\section{A experiência do Curso de Terapia Ocupacional de Ribeirão Preto}

A proposta de formação de fóruns intersetoriais para discutir e elaborar políticas públicas também de implementação intersetorial tem guiado a elaboração da prática da Terapia Ocupacional em contextos sociais do curso de TO-FMRPUSP, centralizada pelo recém-instituído Laboratório de Estudo e Extensão em Terapia Ocupacional Social e Comunidade - Communitas, do referido curso, bem como tem orientado uma metodologia de açáo no sentido de busca constante da constituição de articulaçóes intersetoriais, na comunidade e no território, da criação de estratégias de ação voltadas para a atenção à população atendida nos estágios profissionalizantes, nesses contextos sociais. A partir das atividades do estágio profissional, os estagiários são orientados a buscar articulaçôes junto a iniciativas e serviços para além da assistência social, campo no qual estão atuando, tais como articulaçóes com setores da educação, saúde, esporte e cultura, para acionar serviços e ações de inclusão em iniciativas organizadas nesses setores.

Assim como busca-se nas práticas de estágio estimular o contato periódico dos estagiários com outras organizações de capacitação e formação profissional, administrativas e jurídicas, na perspectiva de fomentar no aluno iniciativas articuladoras que busquem recursos territoriais, comunitários para melhoria de qualidade de vida da população atendida, representação pública e auto-organização, na busca de soluçôes de problemas, para a inclusão e emancipação dessa população.

A partir do evento científico promovido pelo curso de TO-FMRPUSP em agosto de $2012 \mathrm{e}$ através da nossa participação junto ao CREAS-POP e junto à Secretaria Municipal de Assistência Social de Ribeirão Preto, nossa prática tem procurado estabelecer meios de comunicação através de fóruns de discussão intersetoriais, principalmente entre as secretarias municipais de Assistência Social, de Saúde, Educação, Cultura, Meio Ambiente e Urbanização, Esporte e entre a sociedade civil, como ONGs e outras. Tem-se proposto açóes articuladas entre essas secretarias no sentido de aumentar o acesso de pessoas 
e grupos em vulnerabilidade social aos serviços e equipamentos coletivos, da criação de políticas sociais de enfrentamento à pobreza e de mecanismos de inclusão social. Além do documento entregue às várias secretarias, Prefeitura, Câmara de Vereadores, têm-se intensificado discussóes sobre políticas públicas, articuladas junto ao Fórum Social de Ribeirão Preto. Essa organização reúne várias outras, cujos principais expoentes são os representantes do Centro Brasileiro de Estudos de Saúde (CEBES-subsede Ribeirão Preto) e representantes de movimentos sociais do município de Ribeirão Preto que, inclusive, participaram do evento científico e da comissão que elaborou o documento citado.

Outra iniciativa, em desenvolvimento, é uma pesquisa científica patrocinada pela Pró-Reitoria de Cultura e Extensão da Universidade de São Paulo e pela FAEPA - Fundação de Apoio ao Ensino e Pesquisa e Assistência do HC da FRMPUSP, coordenada pela autora deste trabalho e demais docentes do curso de TO-FMRPUSP, que busca estudar e compreender as situaçóes de ruptura com as redes de suporte social e das relaçóes de trabalho de pessoas em situação de rua no município de Ribeirão Preto. A partir dos dados coletados por meio de entrevistas e depoimentos filmados de pessoas que estavam morando na rua, está sendo desenvolvido um videodocumentário que será usado como dispositivo de discussão e disseminação potente da questão social e política ligada à condição de rua e extrema pobreza e às medidas de enfrentamento à vulnerabilidade e exclusão social. Assim, pretende-se que o documentário, ainda em fase de edição, seja exibido em evento especial, no qual se buscará reunir representantes de setores da administração pública e da sociedade civil para disparar processo de articulação para a construção de estratégias intersetoriais de enfrentamento da problemática, mobilizando diferentes atores sociais na construção de projetos, açóes e implementação de políticas públicas de inclusão social e emancipação político-social.

\section{Considerações finais}

A Terapia Ocupacional Social enquanto campo de conhecimento e prática vem apresentando uma proposta metodológica ainda em construção, apesar de já haver um delineamento claro no que diz respeito a determinados aspectos, tais como o descentramento do campo clínico e a inserção na assistência social, a fundação de uma prática social, a superação de uma atuação com base no indivíduo e nos âmbitos institucionais para ampliar formas de atuação nos territórios, juntamente com as comunidades, grupos sociais, entre outros, e, dessa forma, as intervençóes se ampliam para o âmbito da cultura, das relaçóes sociais locais e mais amplas e dos contextos históricos, econômicos e políticos que geram as condiçôes de vida em transformação. Assim como aspectos teórico-metodológicos apontam para a necessidade de uma prática voltada para comunidades, pessoas e grupos que se encontram em determinadas condiçóes nas quais as formas de cidadania, representação pública, inclusão social e acesso aos meios de reprodução da vida social estão comprometidas. E, para isso, uma prática voltada para atuação em nível das políticas públicas e em fóruns institucionais administrativos, nas várias esferas de governo, é necessária e esse âmbito de conhecimento e prática precisa ser inserido nos cursos de graduação em Terapia Ocupacional.

Nessa perspectiva, nós do Curso de TO - FMRPUSP procuramos construir uma prática social dentro do campo da Terapia Ocupacional Social em Ribeiráo Preto focalizando a atenção, nesse momento, na população em vulnerabilidade social, especialmente neste artigo estamos dando enfoque às pessoas em situação de rua, políticas de enfrentamento das condiçóes de pobreza e busca de cidadania plena para tais segmentos e grupos sociais. E, nesse sentido, iniciamos um processo voltado para a construção de fóruns municipais e intersetoriais para discussão do problema, elaboração de políticas públicas e estratégias assistenciais e discussão mais geral voltada para medidas governamentais para erradicação da pobreza e desigualdades sociais. A intersetorialidade englobando setores da administração pública e da sociedade civil, portanto, passa a ser, nesse momento, uma estratégia prioritária de intervenção.

Essa ênfase na formação intersetorial para criar mecanismos de enfrentamento à situação de pobreza e para construir programas para populaçóes em vulnerabilidade social no município de Ribeirão Preto mostra-se como um caminho promissor, pois além de se perceber que a complexidade da problemática em torno das pessoas em situaçáo de rua transcende as barreiras da capacidade de resolução dos setores isoladamente, também se observa que há um isolamento na gestão das políticas públicas e a presença de uma impermeabilidade entre os atores dos diferentes setores. Assim, as principais propostas giram em torno da integração, interação, sinergia e comunicação entre os setores envolvidos, para elaboração e implementação de políticas públicas integradas e resolutivas. 
Para tanto, apresentamos um referencial teóricofilosófico que tem contribuído para balizar um campo de conhecimento e prática no contexto social da atuação terapêutica ocupacional que é o referencial habermasiano da Teoria da Açáo Comunicativa.

Tal referencial propóe, como um de seus aspectos principais, a concepção da comunicação humana como instrumento que contém um potencial intrínseco de propiciar o entendimento mútuo entre homens e mulheres sobre algo no mundo da vida, exatamente por esse se constituir um campo de realização da intersubjetividade humana e dar acesso a construçốes apoiadas em racionalidade não instrumental e sim comunicativa, possibilitando o exercício ético do debate político entre os seres humanos no sentido de construírem consensos que se fundem na criação de caminhos para o Bem Comum. A racionalidade instrumental, nessas condiçôes, não autonomizada, se submeteria à racionalidade comunicativa fundadora dos consensos éticos para a ação social.

Como definimos anteriormente, a intersetorialidade como terreno de interação por excelência traz embutidos uma série de conceitos e elementos que estão na base de sua definição, ou de suas definiçôes, já que não se pode determinar positivamente uma única. Tais elementos seriam: autonomia, inexistência de hierarquia, compartilhamento de objetivos comuns, cooperação, confiança, interdependência e intercâmbio constante e duradouro de recursos e, também, instância ou fórum formador de consensos, já que entre os objetivos fundamentais que justificam a formação intersetorial está a criação de determinados acordos ou consensos entre pessoas que representam determinados setores ou organizaçôes sobre algo no ambiente social em que convivem.

Se pensarmos que a teoria habermasiana concebe a situação ideal de fala como aquela que se dá em circunstâncias especiais nas quais todos os participantes têm iguais oportunidades de expressão e ação, pensamos já nas hierarquias questionadas, na afirmação de seres humanos autônomos, empoderados e democraticamente organizados. Assim, acredita-se que tal referencial representa uma importante contribuição para a prática social que vem se desenvolvendo a partir das estratégias e açôes acadêmicas de ensino, pesquisa e extensáo disponibilizadas e compartilhadas no Laboratório de Estudo e Extensão em Terapia Ocupacional Social e Comunidade do Curso de Terapia Ocupacional da FMRPUSP.

\section{Referências}

ALMEIDA, M. C. et al. Processos e práticas de formalização da terapia ocupacional na assistência social: alguns marcos e desafios. Cadernos de Terapia Ocupacional, São Carlos, v. 20, n. 1, p. 33-41, 2012.

ARAGĀO, L. Habermas: filósofo e sociólogo do nosso tempo. Rio de Janeiro: Tempo Brasileiro, 2002.

AZEVEDO, E.; PELICIONI, M. C. F.; WESTPHAL, M. F. Práticas intersetoriais nas políticas públicas na promoção de saúde. Revista de Saúde Coletiva, Rio de Janeiro, v. 22, v. 4, p. 1333-1356, 2012.

BARROS, D. D.; LOPES, R. E.; GALHEIGO, S. Terapia ocupacional na prática social. In: CAVALCANTI, A.; GALVÃO, C. (Orgs.). Terapia ocupacional: fundamentação \& prática. Rio de Janeiro: Guanabara, 2007. p. 347-352.

CASTEL, R. As dinâmicas do processo de marginalização: da vulnerabilidade à desfiliação. Caderno $C R H$, Salvador, v. 7, n. 26, p. 19-40, 1997.

CASTEL, R. As metamorfoses da questão social: uma crônica do salário. 3. ed. Petrópolis: Vozes, 2001.

CASTELLS, M. A sociedade em rede. 14. ed. São Paulo: Paz e Terra, 2011. (v. 1). PMid:22016835 PMCid:PMC3196287.

FIORATI, R. C. A organização dos serviços extra-hospitalares de saúde mental, o projeto terapêutico e a inserção da reabilitação psicossocial. 2010. 242 f. Tese (Doutorado em Saúde Mental)-Universidade de São Paulo, Ribeirão Preto, 2010.

FIORATI, R. C. As atividades terapêuticas em dois serviços extra-hospitalares de saúde mental: a inserção das açôes psicossociais. Cadernos de Terapia Ocupacional, São Carlos, v. 20, n. 2, p. 207-215, 2012.

HABERMAS, J. Técnica e ciência como ideologia. Lisboa: Ediçōes 70, 1987.

HABERMAS, J. Teoría de la acción comunicativa. Madrid: Taurus, 1988.

HABERMAS, J. Consciência moral e agir comunicativo. Rio de Janeiro: Tempo Brasileiro, 1989. PMid:2658414.

HABERMAS, J. A ética da discussão e a questão da verdade. São Paulo: Martins Fontes, 2007.

HABERMAS, J. Sobre a constituição da Europa: um ensaio. Tradução de Denilson Luis Werle, Luiz Repa e Rúrion Melo. São Paulo: Editora UNESP, 2012.

MAGALHÃES, R. et al. Intersetorialidade, convergência e sustentabilidade: desafios do Programa Bolsa Família de Manguinhos-RJ. Ciência \& Saúde Coletiva, Rio de Janeiro, v. 16, n. 11, p. 4443-4453, 2011.

MALFITANO, A. P. Campos e núcleos de intervenção na terapia ocupacional social. Revista de Terapia Ocupacional da USP, São Paulo, v. 16, n. 1, p. 1-8, 2005.

MENDES, E. V. As redes de atenção à saúde. Brasília: Organização Pan-Americana da Saúde, 2011. 
MINAYO-GOMES, C. Produção de conhecimento e intersetorialidade em prol das condiçóes de vida e de saúde dos trabalhadores do setor sucroalcooleiro. Ciência \& Saúde Coletiva, Rio de Janeiro, v. 16, n. 8, p. 3361-3368, 2011.

NASCIMENTO, S. Reflexôes sobre a intersetorialidade entre as políticas públicas. Serviço Social \& Sociedade, São Paulo, n. 101, p. 95-120, 2010.

NAVARRO, N. A intersetorialidade como modelo de gestão das políticas de combate à pobreza no Brasil: $\mathrm{O}$ Caso do Programa Bolsa Família no Município de Guarulhos. 2011. 166 f. Dissertação (Mestrado em
Administração Pública e Governo)-Fundação Getúlio Vargas, São Paulo, 2011.

SORJ, B.; MARTUCCELLI, D. O desafio latino-americano: coesão social e democracia. Rio de Janeiro: Civilização Brasileira, 2008.

SOUZA, J. C. (Org.). Filosofia, racionalidade, democracia: os debates Rorty \& Habermas. São Paulo: Editora UNESP, 2005. http://dx.doi.org/10.7476/9788539303069 WIGGERSHAUS, R. A Escola de Frankfurt: história, desenvolvimento teórico, significação política. Rio de Janeiro: DIFEL, 2006. 